\title{
Synthesis and Characterization of the Rare-Earth Hybrid Double Perovskites: $\left(\mathrm{CH}_{3} \mathrm{NH}_{3}\right)_{2} \mathrm{KGdCl}_{6}$ and $\left(\mathrm{CH}_{3} \mathrm{NH}_{3}\right)_{2} \mathrm{KYCl}_{6}$
}

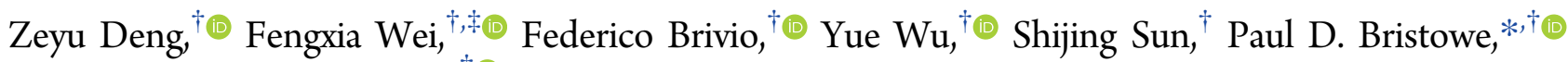 \\ and Anthony K. Cheetham* ${ }^{* \dagger}$ 이 \\ ${ }^{\dagger}$ Department of Materials Science and Metallurgy, University of Cambridge, 27 Charles Babbage Road, Cambridge CB3 0FS, United
Kingdom
${ }^{\ddagger}$ Institute of Materials Research and Engineering, Agency for Science, Technology and Research, 2 Fusionopolis Way, Singapore
}

Supporting Information

ABSTRACT: Two hybrid rare-earth double perovskites, $\left(\mathrm{CH}_{3} \mathrm{NH}_{3}\right)_{2} \mathrm{KGdCl}_{6}$ and $\left(\mathrm{CH}_{3} \mathrm{NH}_{3}\right)_{2} \mathrm{KYCl}_{6}$, have been synthesized by a solution evaporation method and their structures determined by variable temperature single-crystal X-ray diffraction. The diffraction results show that at room temperature both perovskites adopt a rhombohedral structure with $R \overline{3} m$ symmetry, as found previously for $(\mathrm{MA})_{2} \mathrm{KBiCl}_{6}$, and lattice parameters of $a=7.7704(5) \AA$ and $c=20.945(2) \AA$ for $(\mathrm{MA})_{2} \mathrm{KGdCl}_{6}$ and $a=$ $7.6212(12) \AA$ and $c=20.742(4) \AA$ for $(\mathrm{MA})_{2} \mathrm{KYCl}_{6}$. Both phases exhibit a rhombohedral-to-cubic phase transition on heating to $\sim 435 \mathrm{~K}$ for $(\mathrm{MA})_{2} \mathrm{KYCl}_{6}$ and $\sim 375 \mathrm{~K}$ for $(\mathrm{MA})_{2} \mathrm{KGdCl}_{6}$. Density functional calculations on the rhombohedral phase indicate that both materials have large direct band gaps, are mechanically stable, and, in the case of $(\mathrm{MA})_{2} \mathrm{KGdCl}_{6}$, could exhibit magnetic ordering at low temperatures.

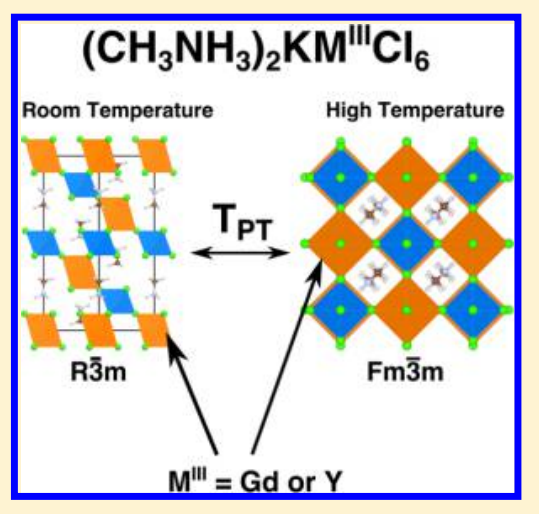

$\mathrm{H}$ alide perovskites of general formula $\mathrm{AM}^{\mathrm{II}} \mathrm{X}_{3}(\mathrm{~A}=$ amine or alkali metal cation; $\mathrm{M}^{\mathrm{II}}=$ divalent cation; $\left.\mathrm{X}=\mathrm{Cl}, \mathrm{Br}, \mathrm{I}\right)$ have emerged as potentially useful light-absorbing materials for solar cell applications due to their very favorable optoelectronic properties. ${ }^{1,2}$ Many examples exist, but most are lead-based and typified by the hybrid organic-inorganic perovskite, $\mathrm{CH}_{3} \mathrm{NH}_{3} \mathrm{PbI}_{3}$, and its inorganic analogue, $\mathrm{CsPbI}_{3}$. However, the toxicity of lead and the instability of these phases has led to a search for $\mathrm{Pb}$-free alternatives. A simple chemical way of achieving this while retaining the favorable optoelectronic properties is to form a halide double perovskite $\left(\mathrm{A}_{2} \mathrm{M}^{\mathrm{I}} \mathrm{M}^{\mathrm{III}} \mathrm{X}_{6}\right)$, also known as elpasolite, in which $\mathrm{M}^{\mathrm{I}}$ and $\mathrm{M}^{\mathrm{III}}$ are monovalent and trivalent cations, respectively. The emergence of halide double perovskites (HDPs) began at the end of the 1960s with the synthesis of $\mathrm{Cs}_{2} \mathrm{NaAmCl}_{6}$ and $\mathrm{Cs}_{2} \mathrm{NaBkCl}_{6}{ }^{3,4}$ This was closely followed by the preparation and characterization of over 20 similar Cs-Na-based HDPs: $\mathrm{Cs}_{2} \mathrm{NaMCl}_{6}(\mathrm{M}=$ lanthanides, $\mathrm{Bi}, \mathrm{Fe}$, etc.). ${ }^{5}$ Motivated by these studies, a significant number of new double perovskites were subsequently explored, ${ }^{6}$ with interest mostly focusing on understanding the optical absorption, emission, and magnetism in structures containing $\mathrm{M}^{\mathrm{III}}$ rare-earth elements. ${ }^{7,8}$ Compared with single perovskites, double perovskites have a broader chemical diversity because both the $\mathrm{M}^{\mathrm{I}}$ and $\mathrm{M}^{\mathrm{III}}$ sites can be modified. Although there have been many reports of inorganic rare-earth HDPs (e.g., $\mathrm{Cs}_{2} \mathrm{LiYCl}_{6}, \mathrm{Cs}_{2} \mathrm{NaGdCl}_{6}, \mathrm{Cs}_{2} \mathrm{NaYF}_{6}{ }^{7,9-11}$ ), including several recent bismuth and indium-containing structures such as $\mathrm{Cs}_{2} \mathrm{AgBiCl}_{6}, \mathrm{Cs}_{2} \mathrm{AgBiBr}_{6}$, and $\mathrm{Cs}_{2} \mathrm{AgInCl}_{6}{ }^{12-15}$ only four hybrid halide double perovskites (HHDPs) have been reported to date: $(\mathrm{MA})_{2} \mathrm{KBiCl}_{6},(\mathrm{MA})_{2} \mathrm{TlBiBr}_{6},(\mathrm{MA})_{2} \mathrm{AgBiBr}_{6}$, and
(MA) ${ }_{2} \mathrm{AgSbI}_{6} \cdot{ }^{16-19}$ Combining the complex interactions between amine and cavity introduced by polar organic cations such as $\mathrm{MA}^{+}$(methylammonium, $\mathrm{CH}_{3} \mathrm{NH}_{3}{ }^{+}$) with rare-earth or transition element metals is a promising route to multiferroic HHDPs. $^{20}$ In this work we describe the synthesis and characterization of two novel HHDPs, (MA) ${ }_{2} \mathrm{KGdCl}_{6}$ and $(\mathrm{MA})_{2} \mathrm{KYCl}_{6}$. Although low-dimensional rare-earth hybrid perovskites have been reported previously, ${ }^{21}$ we believe that these are the first examples of 3D HHDPs. Their structures were characterized using variable-temperature single-crystal Xray diffraction (VT-SCXRD), and density functional theory (DFT) calculations have been used to predict the electronic and mechanical properties of these phases. Details of the computational method are given in the Supporting Information (SI).

$(\mathrm{MA})_{2} \mathrm{KGdCl}_{6}$ and $(\mathrm{MA})_{2} \mathrm{KYCl}_{6}$, both of which are colorless and transparent, have rhombohedral $(R \overline{3} \mathrm{~m})$ symmetry at room temperature, as found previously ${ }^{16}$ for $(\mathrm{MA})_{2} \mathrm{KBiCl}_{6}$, with lattice parameters of $a=7.7704(5) \AA, c=20.945(2) \AA$ for $(\mathrm{MA})_{2} \mathrm{KGdCl}_{6}$ and $a=7.6212(12) \AA, c=20.742(4) \AA$ for $(\mathrm{MA})_{2} \mathrm{KYCl}_{6}$. As in the previous work on the bismuth compound, the inorganic framework of each HHDP was found to be a network of alternating, corner-sharing $\mathrm{KCl}_{6}$ and $\mathrm{MCl}_{6}$ octahedra (Figure 1a,b), with the $\mathrm{MA}^{+}$cations positioned inside the inorganic cages. The orientation of the $\mathrm{C}-\mathrm{N}$ bond

Received: August 31, 2017

Accepted: September 27, 2017

Published: September 27, 2017 


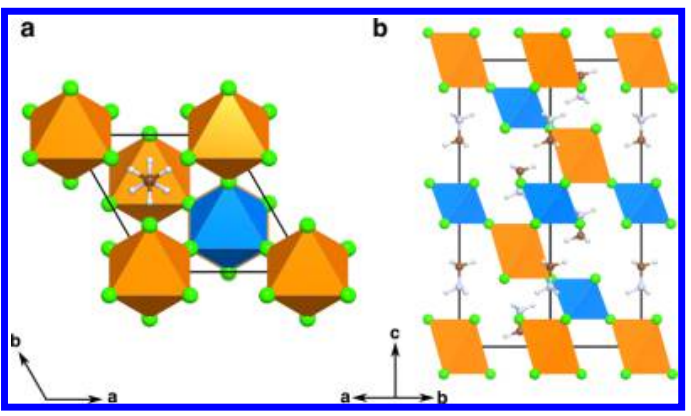

Figure 1. Conventional unit cells of rhomobohedral $(\mathrm{MA})_{2} \mathrm{KMCl}_{6}(\mathrm{M}$ $=\mathrm{Gd}$ and $\mathrm{Y}$ ) at room temperature viewed (a) along the $c$ axis and (b) parallel to the $a-b$ plane. $\mathrm{KCl}_{6}$ and $\mathrm{MCl}_{6}$ octahedra are shown in orange and blue, respectively. Green: $\mathrm{Cl}$, brown: $\mathrm{C}$, light blue: $\mathrm{N}$, silver: $\mathrm{H}$.

alternates along the $c$ axis. Bond lengths indicate that the $\mathrm{Cl}$ atoms are closer to $\mathrm{Gd} / \mathrm{Y}$ than $\mathrm{K}$ (Table S1). Because of the relative sizes of the $\mathrm{M}^{\mathrm{III}}$ cations $\left(\mathrm{Gd}^{3+}: 93.8 \mathrm{pm}\right.$ and $\mathrm{Y}^{3+}: 90$ $\left.\mathrm{pm}^{22}\right)$, (MA $)_{2} \mathrm{KGdCl}_{6}\left(V=1095.21(18) \AA^{3}\right)$ has a slightly larger unit cell volume than $(\mathrm{MA})_{2} \mathrm{KYCl}_{6}\left(V=1043.4(4) \AA^{3}\right)$. The tolerance factors ${ }^{23}$ of $(\mathrm{MA})_{2} \mathrm{KYCl}_{6}$ and $(\mathrm{MA})_{2} \mathrm{KGdCl}_{6}$ are 0.954 and 0.948 , respectively, indicating that $(\mathrm{MA})_{2} \mathrm{KYCl}_{6}$ is slightly more close-packed and that both are more close-packed than $(\mathrm{MA})_{2} \mathrm{KBiCl}_{6}(0.933)$. Table $\mathrm{S} 1$ shows that the lattice parameters predicted by DFT using the optB86b+vdW functional agree well with the experimental observations for both structures, and it is seen that optB86b+vdW gives the best equilibrium volume and $c / a$ ratio when compared with the crystallographic results for $(\mathrm{MA})_{2} \mathrm{KYCl}_{6}$ (Table S2). Within the $\left[\mathrm{KMCl}_{6}\right]^{2-}$ inorganic framework, the $d_{\mathrm{K}-\mathrm{Cl}}, d_{\mathrm{M}-\mathrm{Cl}}$ bond distances and $\mathrm{K}-\mathrm{Cl}-\mathrm{M}$ bond angles also match well with the SCXRD structure. The main discrepancy between the experiments and the calculations concerns the apparent overestimation of $d_{\mathrm{C}-\mathrm{N}}$, as the crystallographic $\mathrm{C}-\mathrm{N}$ distances represent the time-averaged positions of the electron densities and are shortened by the librations of the $\mathrm{MA}^{+}$cation about the $c$ axis (Figure 2a).
Synthesis and characterization of the HHDPs was found to be challenging because both materials are deliquescent, similar to the inorganic rare-earth HDPs. ${ }^{6}$ In powder form the crystals dissolve quickly (minutes) when exposed to normal laboratory atmosphere. Because of this, the samples were not pure and contained some starting materials, which leads to difficulties for powder characterization. The synthesis temperature was found to be important because too low a temperature $\left(<70{ }^{\circ} \mathrm{C}\right)$ during evaporation results in the formation of rare-earth chloride hexahydrates in the product. Too high a temperature $\left(>100{ }^{\circ} \mathrm{C}\right)$ produced twinned crystals. To understand better the relative stabilities of the two rare-earth HHDPs, their decomposition and formation enthalpies $\left(\Delta H_{d}\right.$ and $\left.\Delta H_{\mathrm{f}}\right)$ were calculated, as defined in the SI, and are given in Table 1.

Table 1. DFT-Calculated (optB86b+vdW) Decomposition Enthalpies $\left(\Delta H_{d}\right)$ and Formation Enthalpies $\left(\Delta H_{\mathrm{f}}\right)$ of Rhombohedral (MA) ${ }_{2} \mathrm{KGdCl}_{6},(\mathrm{MA})_{2} \mathrm{KYCl}_{6}$, and $(\mathrm{MA})_{2} \mathrm{KBiCl}_{6}{ }^{a}$

$\begin{array}{lccc} & (\mathrm{MA})_{2} \mathrm{KGdCl}_{6} & (\mathrm{MA})_{2} \mathrm{KYCl}_{6} & (\mathrm{MA})_{2} \mathrm{KBiCl}_{6} \\ \Delta H_{\mathrm{d}} & 6.56 & 23.52 & 18.76 \\ \Delta H_{\mathrm{f}} & -634.81 & -949.48 & -719.69\end{array}$

${ }^{a}$ Units are $\mathrm{meV} /$ atom.

Positive values of $\Delta H_{\mathrm{d}}$ and negative values of $\Delta H_{\mathrm{f}}$ suggest that they are energetically favorable. It is seen that $(\mathrm{MA})_{2} \mathrm{KYCl}_{6}$ is more stable than both $(\mathrm{MA})_{2} \mathrm{KGdCl}_{6}$ and the previously synthesized $(\mathrm{MA})_{2} \mathrm{KBiCl}_{6} \cdot{ }^{16}$ The latter result is interesting because experimentally we found $(\mathrm{MA})_{2} \mathrm{KBiCl}_{6}$ to be much easier to synthesize than its rare-earth counterparts. This is probably because of the synthesis environment and kinetics, which are ignored in DFT calculations. It is well known that rare-earth halides $\left(\mathrm{M}^{\mathrm{III}} \mathrm{X}_{3}\right)$ are extremely hydroscopic and can readily form hydrates because $\mathrm{M}-\mathrm{X}$ bonds, which are also present in the HHDPs, are easily attacked by water. ${ }^{6}$

The VT-SCXRD results are shown in Tables S3 and S4. Like $(\mathrm{MA})_{2} \mathrm{KBiCl}_{6}$, the $(\mathrm{MA})_{2} \mathrm{KGdCl}_{6}$ and $(\mathrm{MA})_{2} \mathrm{KYCl}_{6}$ perovskites transform from a rhombohedral structure $(R \overline{3} m)$ to a face-

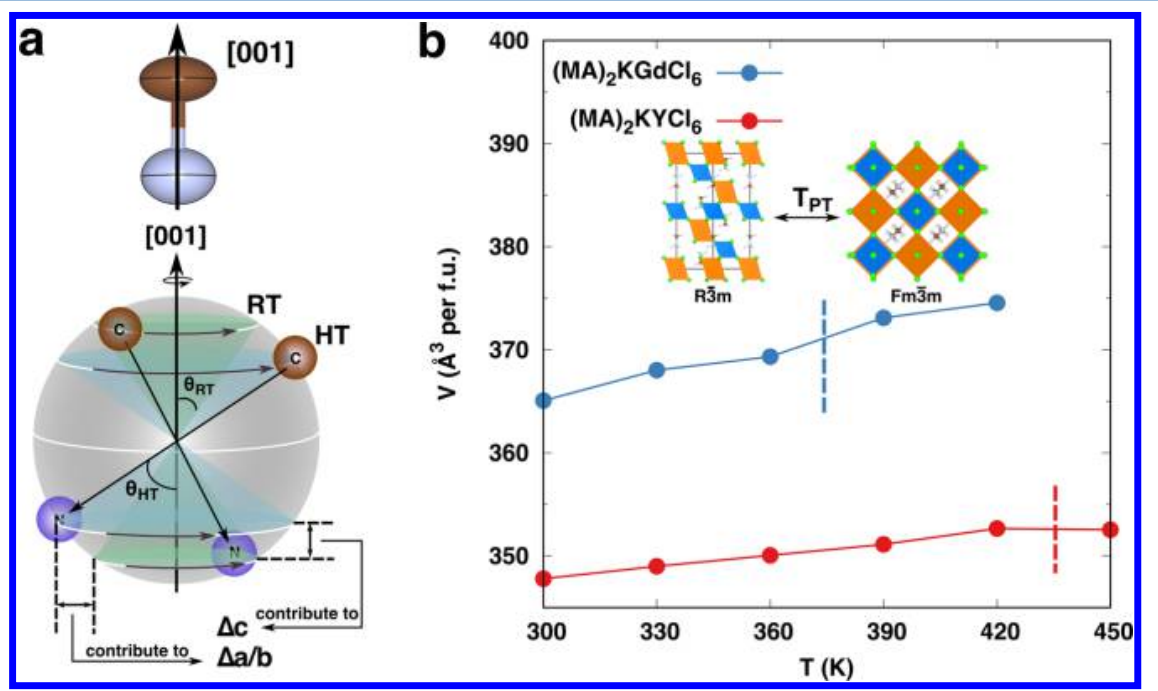

Figure 2. (a) Upper: the experimental disk-shaped thermal ellipsoid of the $\mathrm{C}-\mathrm{N}$ bond. Lower: illustration of how the libration of the $\mathrm{MA}^{+}$cation about the $c$ axis contributes to the lattice parameters at room temperature (RT) and high temperature (HT). The libration angles at HT and LT are labeled as $\theta_{\mathrm{HT}}$ and $\theta_{\mathrm{LT}}$ (b) Volumes per formula unit (f.u.) of (MA) ${ }_{2} \mathrm{KGdCl}_{6}$ and $(\mathrm{MA})_{2} \mathrm{KYCl}_{6}$ upon heating measured by VT-SCXRD. The approximate rhombohedral-cubic phase-transition temperatures $T_{\mathrm{PT}}$ are marked by vertical dashed lines. 
centered cubic structure $(F m \overline{3} m)$ on heating above room temperature (unpublished results). The phase-transition temperature, $T_{\mathrm{PT}}$, for $(\mathrm{MA})_{2} \mathrm{KGdCl}_{6}$ is between 360 and 390 $\mathrm{K}$, whereas for $(\mathrm{MA})_{2} \mathrm{KYCl}_{6}$ it is between 420 and $450 \mathrm{~K}$. The higher $T_{\mathrm{PT}}$ for $(\mathrm{MA})_{2} \mathrm{KYCl}_{6}$ may partly originate from its stronger hydrogen bonding. As discussed in the previous work $^{16}$ on $(\mathrm{MA})_{2} \mathrm{KBiCl}_{6}$, the $\mathrm{N} \cdots \mathrm{Cl}$ distance can be used as an indicator of hydrogen-bond strength: The shorter this distance, the closer the amine group is to the $\mathrm{Cl}$ anions and the stronger the $\mathrm{Cl} \cdots \mathrm{H}$ bonding. In Table $\mathrm{S} 1$ we show that $d_{\mathrm{N} \cdots \mathrm{Cl}}$ is $3.397(10) \AA$ and $3.341(11) \AA$ for $(\mathrm{MA})_{2} \mathrm{KGdCl}_{6}$ and $(\mathrm{MA})_{2} \mathrm{KYCl}_{6}$, respectively, implying that the latter has stronger hydrogen bonds. The different thermal expansion coefficients of the two rare-earth double perovskites can also be rationalized by the different stiffnesses, ${ }^{24}$ as discussed further below. Upon heating, both $(\mathrm{MA})_{2} \mathrm{KMCl}_{6}$ perovskites increase in volume, as shown in Figure $2 \mathrm{~b}$ and Tables S3 and S4. However, although the $a$ (and $b$ ) lattice parameters increase, the $c$ lattice parameter decreases with temperature (Tables S3 and S4). This results in a negative thermal expansion coefficient along $c$ (Table 2) and a

Table 2. Linear and Volume Thermal Expansion Coefficients $(\alpha)$ for Rhombohedral (MA) ${ }_{2} \mathrm{KMCl}_{6}$ Fitted from VTSCXRD Data ${ }^{a}$

$\begin{array}{lccc} & \alpha_{a} & \alpha_{c} & \alpha_{\mathrm{V}} \\ (\mathrm{MA})_{2} \mathrm{KGdCl}_{6} & 47.75 & -36.76 & 65.81 \\ (\mathrm{MA})_{2} \mathrm{KYCl}_{6} & 29.79 & -25.21 & 29.42\end{array}$

${ }^{a}$ Linear coefficients are fitted using data from 300 to $360 \mathrm{~K}(420 \mathrm{~K})$ for $(\mathrm{MA})_{2} \mathrm{KGdCl}_{6}\left((\mathrm{MA})_{2} \mathrm{KYCl}_{6}\right)$, whereas the volume coefficients are fitted using all data points. Units are $10^{-4} / \mathrm{K}$.

decrease in the $c / a$ ratio for both materials. The effect is larger for $(\mathrm{MA})_{2} \mathrm{KGdCl}_{6}$ than for $(\mathrm{MA})_{2} \mathrm{KYCl}_{6}$ and is also observed in $(\mathrm{MA})_{2} \mathrm{KBiCl}_{6}$. The interatomic bond distances mostly increase upon heating, except for $d_{\mathrm{C}-\mathrm{N}}$, which is correlated to the negative thermal expansion along the $c$ axis. Because the positions of the $\mathrm{C}$ and $\mathrm{N}$ atoms are refined at the $6 c$ site due to the constraint of symmetry, $d_{\mathrm{C}-\mathrm{N}}$ reflects the projection of the average $\mathrm{C}-\mathrm{N}$ positions onto the $c$ axis. The anisotropic displacement ellipsoids of $\mathrm{C}$ and $\mathrm{N}$ deduced from SCXRD are disk-shaped and aligned normal to [001] (Figure 2a, top), which indicates that the $\mathrm{MA}^{+}$cations are librating off the $c$ axis. The libration angle increases with temperature, making the projected $d_{\mathrm{C}-\mathrm{N}}$ smaller. This libration, which is transmitted through the interaction between amine and cavity to the $\left[\mathrm{KMCl}_{6}\right]^{2-}$ framework, combined with the vibrations of the $\mathrm{M}-\mathrm{Cl}$ octahedra, is responsible for the observed decrease in $c$ and increase in $a$ (and $b$ ) upon heating (Figure 2a, bottom).

The DFT-calculated (optB86b-vdW+SOC) electronic band structures together with the projected density of states (PDOS) for both rare-earth HHDPs in their rhombohedral structure are shown in Figure 3a,b and look very similar. Both perovskites possess large direct band gaps at the $\Gamma$ point, with $4.91 \mathrm{eV}$ for $(\mathrm{MA})_{2} \mathrm{KGdCl}_{6}$ and $5.04 \mathrm{eV}$ for $(\mathrm{MA})_{2} \mathrm{KYCl}_{6}$. The large band gaps are due to the strongly ionic nature of the $\mathrm{K}^{+}$cation and the presence of $\mathrm{Cl}^{-}$, which has a higher electronegativity and smaller ionic radius than bromine or iodine. ${ }^{17}$ Focusing on the orbitals that contribute to the band edge states, Figure $3 \mathrm{~b}$ shows that the valence band maximum (VBM) of both HHDPs is dominated by $\mathrm{Cl} 3 \mathrm{p}$ nonbonding states, whereas the conduction band minimum $(\mathrm{CBM})$ for $(\mathrm{MA})_{2} \mathrm{KGdCl}_{6}$ and $(\mathrm{MA})_{2} \mathrm{KYCl}_{6}$ is characterized by $\mathrm{Gd} 5 \mathrm{~d}-\mathrm{Cl} 3 \mathrm{p}$ and $\mathrm{Y} 4 \mathrm{~d}-\mathrm{Cl} 3 \mathrm{p}$ bonding states, respectively. The energy states of the $\mathrm{MA}^{+}$and $\mathrm{K}^{+}$cations are localized and energetically inactive, as found previously ${ }^{16}$ for $(\mathrm{MA})_{2} \mathrm{KBiCl}_{6}$. One difference between the two HHDPs is the presence of $\mathrm{Gd} 4 \mathrm{f}$ electrons in $(\mathrm{MA})_{2} \mathrm{KGdCl}_{6}$, but these are deep and localized at around $-7 \mathrm{eV}$, forming seven extremely flat bands. The direct nature of the band gaps in both materials is related to the $\mathrm{Cl} 3 \mathrm{p}$ nonbonding states that dominate the VBM. This is different from other hybrid halide perovskites, such as (MA) $\mathrm{PbBr}_{3}$ and $(\mathrm{MA})_{2} \mathrm{TlBiBr}_{6}$, where the direct band gaps are strongly related to the $\mathrm{Pb}$ and $\mathrm{Tl}$ 6s lone pairs. ${ }^{17}$ Direct band gaps are important in optoelectronic

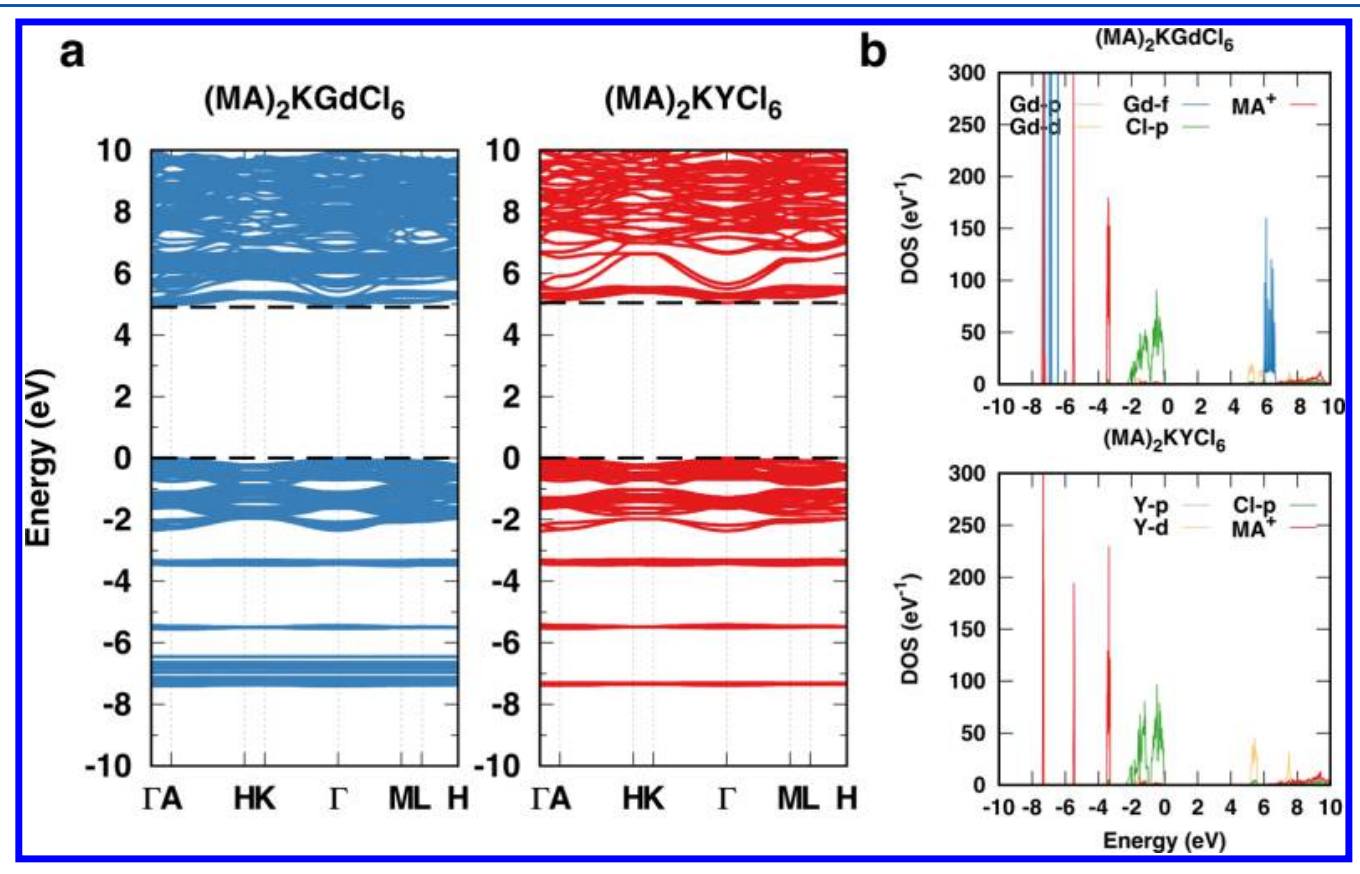

Figure 3. DFT-calculated (a) electronic band structures and (b) projected densities of states (PDOS) for (MA) ${ }_{2} \mathrm{KGdCl}_{6}$ and $\left(\mathrm{MA}_{2} \mathrm{KYCl}_{6}\right.$. Valence band maximum (VBM) is set as zero. 
Table 3. DFT-Calculated (optB86b+vdW) Polycrystalline ${ }^{26}$ Young's Modulus (E), Bulk Modulus (B), Shear Modulus (G), and Poisson's Ratio $(\nu)$ for Rhombohedral $(\mathrm{MA})_{2} \mathrm{KGdCl}_{6},(\mathrm{MA})_{2} \mathrm{KYCl}_{6}$, and $(\mathrm{MA})_{2} \mathrm{KBiCl}_{6}{ }^{16}$ and Their Single-Crystal Maximum Values $^{a}$

\begin{tabular}{|c|c|c|c|c|c|c|c|c|c|c|}
\hline & $E$ & B & G & $\nu$ & $E_{\max }$ & $E_{\min }$ & $G_{\max }$ & $G_{\min }$ & $\nu_{\min }$ & $\nu_{\max }$ \\
\hline$(\mathrm{MA})_{2} \mathrm{KGdCl}_{6}$ & 26.03 & 19.63 & 10.18 & 0.28 & 37.1 & 19.93 & 15.25 & 6.56 & 0.59 & 0.19 \\
\hline$(\mathrm{MA})_{2} \mathrm{KYCl}_{6}$ & 27.38 & 19.7 & 10.79 & 0.27 & 36.78 & 22.02 & 15.28 & 7.76 & 0.51 & 0.14 \\
\hline$(\mathrm{MA})_{2} \mathrm{KBiCl}_{6}$ & 24.03 & 18.75 & 9.34 & 0.29 & 35.17 & 15.29 & 14.78 & 6.28 & 0.50 & 0.10 \\
\hline
\end{tabular}

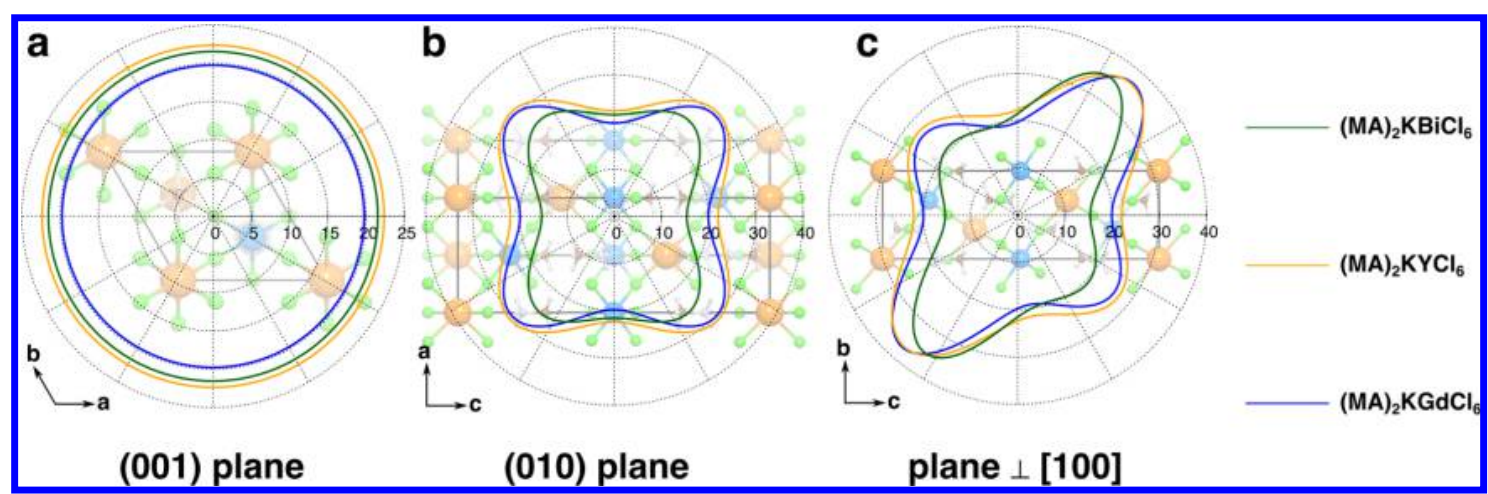

Figure 4. DFT-calculated polar plots of the directional Young's modulus of $(\mathrm{MA})_{2} \mathrm{KMCl}_{6}(\mathrm{M}=\mathrm{Y}$ : orange and Gd: blue $)$ as well as previously reported $(\mathrm{MA})_{2} \mathrm{KBiCl}_{6}$ (green) projected on (a) the (001) plane, (b) the (010) plane, and (c) the plane perpendicular to [100]. Radii indicate the value of directional Young's modulus and units are GPa. Structure of $(\mathrm{MA})_{2} \mathrm{KYCl}_{6}$ is shown under the plots.

applications because optical absorption and emission processes become much easier. Although the band gaps in the present rare-earth HHDPs are too large to be used in solar cells, other applications such as solid-state lighting may be possible by doping the materials with further rare-earth elements (e.g., $\mathrm{Ce}^{3+}, \mathrm{Tb}^{3+}$, or $\left.\mathrm{Eu}^{3+}\right)$, as previously demonstrated in oxide garnet systems. ${ }^{25}$

The presence of $\mathrm{Gd}$ in $(\mathrm{MA})_{2} \mathrm{KGdCl}_{6}$ suggests that this HHDP could exhibit magnetic ordering due to unpaired $4 f$ electrons. To examine this possibility, spin-polarized DFT calculations were performed on supercells of the primitive cell (i.e., containing two and four Gd atoms respectively). After optimization of the atomic, electronic, and magnetic structures, it was found that the difference in energy between the ferromagnetic (FM), antiferromagnetic (AFM), and paramagnetic (PM) states was very small ( 0.1 to $0.2 \mathrm{meV} /$ f.u. $)$, with the AFM structure being slightly more stable. In each case the magnetic moment $\left(S_{z}\right)$ of each Gd atom was $|6.88| \mu_{\mathrm{B}}$. The small difference in energy between the states suggests that $(\mathrm{MA})_{2} \mathrm{KGdCl}_{6}$ may be paramagnetic down to very low temperatures. This situation appears to be similar to that found experimentally ${ }^{8}$ for $\mathrm{Cs}_{2} \mathrm{NaGdCl}_{6}$, which is thought to be paramagnetic above ca. $35 \mathrm{mK}$ and ferromagnetic below. As shown in Figure $3 b$, the $4 \mathrm{f}$ electrons in the valence band are energetically deep and localized, suggesting a weak magnetic exchange effect and an extremely low Curie temperature. Although $(\mathrm{MA})_{2} \mathrm{KGdCl}_{6}$ is cation-ordered and centrosymmetric at room temperature, the presence of the polar $\mathrm{MA}^{+}$cation may cause it to change symmetry on cooling and become ferroelectric. Consequently, there is a potential for $(\mathrm{MA})_{2} \mathrm{KGdCl}_{6}$ to be multiferroic at low temperatures. The small energy difference between the magnetic states may also mean that it could be used as a magnetocaloric coolant.

Optoelectronic devices usually contain interfaces between mechanically different materials, and thus it is important to understand the elastic properties of HHDPs. The DFT- calculated elastic constants of the two rare-earth HHDPs are shown in Table S5, and the polycrystalline elastic moduli are given in Table 3. Both perovskites are mechanically stable because all of the elements in the eigenvectors of their elastic constant matrices are positive. Like other halide perovskites, ${ }^{16-18,27,28}$ they exhibit relatively low elastic moduli, with $(\mathrm{MA})_{2} \mathrm{KYCl}_{6}$ being slightly stiffer than $(\mathrm{MA})_{2} \mathrm{KGdCl}_{6}$, with DFT-calculated Young's moduli along $<100>$ of 22.34 and 19.73 GPa, respectively. The flexible hybrid double-perovskite structure suggests a flatter energy surface for phase transformations and also explains why $(\mathrm{MA})_{2} \mathrm{KGdCl}_{6}$ has larger thermal expansion coefficients and $(\mathrm{MA})_{2} \mathrm{KYCl}_{6}$ has a higher $T_{\mathrm{PT}}$. The stiffness of the HHDPs is mainly related to the strength of the bonds in the inorganic framework. ${ }^{17}$ Assuming a direct correlation between bond length and bond strength, it is seen (Table S1) that $d_{\mathrm{K}-\mathrm{X}}$ and $d_{\mathrm{M}-\mathrm{X}}$ are shorter in $(\mathrm{MA})_{2} \mathrm{KYCl}_{6}$ compared with $(\mathrm{MA})_{2} \mathrm{KGdCl}_{6}$, which is consistent with the lower calculated Young's modulus in the latter material (Table 3). The calculated single-crystal directional Young's moduli of (MA) ${ }_{2} \mathrm{KYCl}_{6}$ are shown in Figure $4 \mathrm{a}-\mathrm{c}$ projected onto different crystallographic planes. Similar contour maps are found for (MA) ${ }_{2} \mathrm{KGdCl}_{6}$. The directional Young's modulus is seen to be highly anisotropic, especially on the (010) plane and the plane normal to [100] (Figure $4 b, c$ ), with the largest values along the $\mathrm{M}-\mathrm{X}-\mathrm{K}$ direction and the smallest values along the diagonal of the $\mathrm{M}-\mathrm{X}-\mathrm{K}$ pseudo-cubic cage, which is similar to other HHDPs. ${ }^{17}$

In conclusion, two new rare-earth hybrid double perovskites, $(\mathrm{MA})_{2} \mathrm{KGdCl}_{6}$ and $(\mathrm{MA})_{2} \mathrm{KYCl}_{6}$, have been prepared using a solution evaporation method and their structures characterized using variable temperature single-crystal X-ray diffraction. At room temperature both perovskites have rhombohedral symmetry, but on heating above $360 \mathrm{~K}$ they transform to cubic symmetry. This behavior is similar to that found previously for $(\mathrm{MA})_{2} \mathrm{KBiCl}_{6}$. DFT calculations on the rhombohedral phase indicate that the new perovskites have 
large direct band gaps $(\sim 5 \mathrm{eV})$, are mechanically stable, and could exhibit magnetic ordering at low temperature in the case of $(\mathrm{MA})_{2} \mathrm{KGdCl}_{6}$. The discovery of these materials expands the scope of hybrid perovskites to rare-earth containing materials, enabling the possibility of future applications in solid-state lighting and magnetism.

\section{EXPERIMENTAL METHODS}

A solution evaporation method was used to prepare crystals of $(\mathrm{MA})_{2} \mathrm{KYCl}_{6}$ and $(\mathrm{MA})_{2} \mathrm{KGdCl}_{6}$, both of which were colorless and transparent. The materials were synthesized by dissolving $\mathrm{Y}_{2} \mathrm{O}_{3} / \mathrm{Gd}_{2} \mathrm{O}_{3}(1 \mathrm{mmol}), \mathrm{KCl}(1 \mathrm{mmol})$, and $(\mathrm{MA}) \mathrm{Cl}(2 \mathrm{mmol})$ in $2 \mathrm{~mL}$ of $\mathrm{HCl}$ solution (32 wt \%) and placing the solution in a capped glass vial on a hot plate at $80{ }^{\circ} \mathrm{C}$. The solution was stirred for $1 \mathrm{~h}$ at $80^{\circ} \mathrm{C}$ until it became clear and colorless. The cap was then opened and the solution was evaporated until dry at $85{ }^{\circ} \mathrm{C}$. Crystals suitable for SCXRD were chosen from the dried sample. Some secondary phases $\left(\mathrm{YCl}_{3} \cdot 6 \mathrm{H}_{2} \mathrm{O}, \mathrm{GdCl}_{3}\right.$. $6 \mathrm{H}_{2} \mathrm{O}$, and $\mathrm{KCl}$ ) were obtained using this method. Other synthesis methods were therefore tried, including vapor diffusion, slow cooling of the oversaturated solution, and hydrothermal and solid-state reactions, but only the procedure described above was successful. Unfortunately, this prevented us from obtaining phase-pure bulk samples that could be used for magnetic and optical characterization.

VT-SCXRD measurements were conducted on the two materials from $300 \mathrm{~K}$ in intervals of $30 \mathrm{~K}$ up to $450 \mathrm{~K}$. Suitable crystals were selected and mounted using Paratone-N on an Xcalibur/Gemini Ultra diffractometer with an Eos CCD area detector. The structures were solved by direct methods using Olex ${ }^{29}$ with the ShelXS ${ }^{30}$ structure solution program and refined with the ShelXL ${ }^{31}$ refinement package using leastsquares minimization. For the high-temperature cubic structures, the positions of the $\mathrm{H}, \mathrm{C}$, and $\mathrm{N}$ atoms were not refined due to the limited ability of X-ray diffraction to detect light elements in the presence of heavy elements such as Gd and $\mathrm{Y}$.

\section{ASSOCIATED CONTENT}

\section{S Supporting Information}

The Supporting Information is available free of charge on the ACS Publications website at DOI: 10.1021/acs.jpclett.7b02322.

Additional information on computational methodology, comparison of DFT calculated and experimental structural properties, test of different DFT vdW schemes and functionals, VT-SCXRD structural properties, and calculated elastic constants data. (PDF)

Crystallographic information for (MA) ${ }_{2} \mathrm{KGdCl}_{6}$ (CCDC $1571642)$ and $(\mathrm{MA})_{2} \mathrm{KYCl}_{6}(\mathrm{CCDC} 1571643)$ and checkCif/PLATON report. (ZIP)

\section{AUTHOR INFORMATION}

\section{Corresponding Authors}

*P.D.B.: E-mail: pdb1000@cam.ac.uk.

*A.K.C.: E-mail: akc30@cam.ac.uk.

ORCID ${ }^{\circ}$

Zeyu Deng: 0000-0003-0109-9367

Fengxia Wei: 0000-0002-2058-5056

Federico Brivio: 0000-0001-6807-4872

Yue Wu: 0000-0003-2874-8267

Paul D. Bristowe: 0000-0002-3153-1387
Anthony K. Cheetham: 0000-0003-1518-4845

Notes

The authors declare no competing financial interest.

\section{ACKNOWLEDGMENTS}

Z.D. thanks the Cambridge Overseas Trust and the China Scholarship Council for financial support. F.W. is a holder of an A*STAR international fellowship granted by the Agency for Science, Technology and Research, Singapore. S.S. and A.K.C. are grateful to the Ras $\mathrm{Al}$ Khaimah Center for Advanced Materials for funding support. The calculations were performed at the Cambridge HPCS and the U.K. National Supercomputing Service, ARCHER. Access to the latter was obtained via the UKCP consortium and funded by EPSRC under Grant No. EP/P022596/1 (Link to open access computational data DOI:10.17863/CAM.13320).

\section{REFERENCES}

(1) Kojima, A.; Teshima, K.; Shirai, Y.; Miyasaka, T. Organometal halide perovskites as visible-light sensitizers for photovoltaic cells. $L$ Am. Chem. Soc. 2009, 131, 6050-6051.

(2) Lee, M. M.; Teuscher, J.; Miyasaka, T.; Murakami, T. N.; Snaith, H. J. Efficient hybrid solar cells based on meso-superstructured organometal halide perovskites. Science 2012, 338, 643-647.

(3) Bagnall, K. W.; Laidler, J. B.; Stewart, M. A. A. Americium chlorocomplexes. I. Chem. Soc. A 1968, 0, 133-136.

(4) Morss, L. R.; Fuger, J. Preparation and crystal structures of dicesium berkelium hexachloride and dicesium sodium berkelium hexachloride. Inorg. Chem. 1969, 8, 1433-1439.

(5) Morss, L. R.; Siegal, M.; Stenger, L.; Edelstein, N. Preparation of cubic chloro complex compounds of trivalent metals: $\mathrm{Cs}_{2} \mathrm{NaMCl}_{6}$. Inorg. Chem. 1970, 9, 1771-1775.

(6) Meyer, G. The synthesis and structures of complex rare-earth halides. Prog. Solid State Chem. 1982, 14, 141-219.

(7) Tanner, P. A.; Mak, C. S. K.; Edelstein, N. M.; Murdoch, K. M.; Liu, G.; Huang, J.; Seijo, L.; Barandiarán, Z. Absorption and emission spectra of $\mathrm{Ce}^{3+}$ in elpasolite lattices. I. Am. Chem. Soc. 2003, 125, 13225-13233.

(8) Roser, M. R.; Xu, J.; White, S. J.; Corruccini, L. R. Magnetic order in three rare-earth elpasolite compounds $\mathrm{Cs}_{2} \mathrm{NaRCl}_{6}$. Phys. Rev. B: Condens. Matter Mater. Phvs. 1992, 45, 12337-12342.

(9) Morrison, C. A.; Leavitt, R. P.; Wortman, D. E. Crystal-field analysis of triply ionized lanthanides in $\mathrm{Cs}_{2} \mathrm{NaLnCl}_{6}$. L. Chem. Phvs. 1980, 73, 2580-2598.

(10) Ma, C.; Tanner, P. A.; Xia, S.; Yin, M. Analysis of VUV and optical spectra of $\mathrm{Cs}_{2} \mathrm{NaYF}_{6}$ crystals doped with $\mathrm{Tm}^{3+}$. Opt. Mater. 2007, 29, 1620-1624.

(11) Brik, M. G.; Ogasawara, K. Microscopic analysis of the crystal field strength and lowest charge transfer energies in the elpasolite crystals $\mathrm{Cs}_{2} \mathrm{NaYX}_{6}$. Phys. Rev. B: Condens. Matter Mater. Phys. 2006, 74, 045105 .

(12) Slavney, A. H.; Hu, T.; Lindenberg, A. M.; Karunadasa, H. I. A bismuth-halide double perovskite with long carrier recombination lifetime for photovoltaic applications. L. Am. Chem. Soc. 2016, 138, 2138-2141.

(13) Mcclure, E. T.; Ball, M. R.; Windl, W.; Woodward, P. M. $\mathrm{Cs}_{2} \mathrm{AgBiX}_{6}(\mathrm{X}=\mathrm{Br}, \mathrm{Cl})$ - new visible light absorbing, lead-free halide perovskite semiconductors. Chem. Mater. 2016, 28, 1348-1354.

(14) Volonakis, G.; Filip, M. R.; Haghighirad, A. A.; Sakai, N.; Wenger, B.; Snaith, H. J.; Giustino, F. Lead-free halide double perovskites via heterovalent substitution of noble metals. I. Phvs. Chem. Lett. 2016, 7, 1254-1259.

(15) Volonakis, G.; Haghighirad, A. A.; Milot, R. L.; Sio, W. H.; Filip, M. R.; Wenger, B.; Johnston, M. B.; Herz, L. M.; Snaith, H. J.; Giustino, F. $\mathrm{Cs}_{2} \mathrm{InAgCl}_{6}$ : A new lead-free halide double perovskite with direct band gap. I. Phvs. Chem. Lett. 2017, 8, 772-778. 
(16) Wei, F.; Deng, Z.; Sun, S.; Xie, F.; Kieslich, G.; Evans, D. M.; Carpenter, M. A.; Bristowe, P. D.; Cheetham, A. K. The synthesis, structure and electronic properties of a lead-free hybrid inorganicorganic double perovskite $(\mathrm{MA})_{2} \mathrm{KBiCl}_{6}(\mathrm{MA}=$ methylammonium $)$. Mater. Horiz. 2016, 3, 328-332.

(17) Deng, Z.; Wei, F.; Sun, S.; Kieslich, G.; Cheetham, A. K.; Bristowe, P. D. Exploring the properties of lead-free hybrid double perovskites using a combined computational-experimental approach. $I$. Mater. Chem. A 2016, 4, 12025-12029.

(18) Wei, F.; Deng, Z.; Sun, S.; Zhang, F.; Evans, D. M.; Kieslich, G.; Tominaka, S.; Carpenter, M. A.; Zhang, J.; Bristowe, P. D.; et al. Synthesis and properties of a lead-free hybrid double perovskite: $\left(\mathrm{CH}_{3} \mathrm{NH}_{3}\right)_{2} \mathrm{AgBiBr}_{6}$. Chem. Mater. 2017, 29, 1089-1094.

(19) Li, Y.-J.; Wu, T.; Sun, L.; Yang, R.-X.; Jiang, L.; Cheng, P.-F.; Hao, Q.-Q.; Wang, T.-J.; Lu, R.-F.; Deng, W.-Q. Lead-free and stable antimony-silver-halide double perovskite $\left(\mathrm{CH}_{3} \mathrm{NH}_{3}\right)_{2} \mathrm{AgSbI}_{6}$. $\mathrm{RSC}$ Adv . 2017, 7, 35175-35180.

(20) Jain, P.; Ramachandran, V.; Clark, R. J.; Zhou, H. D.; Toby, B. H.; Dalal, N. S.; Kroto, H. W.; Cheetham, A. K. Multiferroic behavior associated with an order-disorder hydrogen bonding transition in metal-organic frameworks (MOFs) with the perovskite $\mathrm{ABX}_{3}$ architecture. I. Am. Chem. Soc. 2009, 131, 13625-13627.

(21) Saparov, B.; Mitzi, D. B. Organic-inorganic perovskites: structural versatility for functional materials design. Chem. Rev. 2016, $116,4558-4596$.

(22) Shannon, R. D. Revised effective ionic radii and systematic studies of interatomic distances in halides and chalcogenides. Acta Crystallogr., Sect. A: Cryst. Phys., Diffr., Theor. Gen. Crustallogr. 1976, 32, 751-767.

(23) Kieslich, G.; Sun, S.; Cheetham, A. K. An extended tolerance factor approach for organic-inorganic perovskites. Chem. Sci. 2015, 6, $3430-3433$.

(24) Li, W.; Thirumurugan, A.; Barton, P. T.; Lin, Z.; Henke, S.; Yeung, H. H. M.; Wharmby, M. T.; Bithell, E. G.; Howard, C. J.; Cheetham, A. K. Mechanical tunability via hydrogen bonding in metalorganic frameworks with the perovskite architecture. I. Am. Chem. Soc. 2014, 136, 7801-7804.

(25) Wu, J. L.; Gundiah, G.; Cheetham, A. K. Structure-property correlations in Ce-doped garnet phosphors for use in solid state lighting. Chem. Phvs. Lett. 2007, 441, 250-254.

(26) Hill, R. The elastic behaviour of a crystalline aggregate. Proc. Phvs. Soc. London, Sect. A 1952, 65, 349-354.

(27) Sun, S.; Fang, Y.; Kieslich, G.; White, T. J.; Cheetham, A. K. Mechanical properties of organic-inorganic halide perovskites, $\mathrm{CH}_{3} \mathrm{NH}_{3} \mathrm{PbX}_{3}(\mathrm{X}=\mathrm{I}, \mathrm{Br}$ and $\mathrm{Cl})$, by nanoindentation. I. Mater. Chem. A 2015, 3, 18450-18455.

(28) Sun, S.; Isikgor, F. H.; Deng, Z.; Wei, F.; Kieslich, G.; Bristowe, P. D.; Ouyang, J.; Cheetham, A. K. Factors influencing the mechanical properties of formamidinium lead halides and related hybrid perovskites. ChemSusChem 2017, DOI: 10.1002/cssc.201700991.

(29) Dolomanov, O. V.; Bourhis, L. J.; Gildea, R. J.; Howard, J. A. K.; Puschmann, H. OLEX2: a complete structure solution, refinement and analysis program. I. Appl. Crystallogr. 2009, 42, 339-341.

(30) Sheldrick, G. M. A short history of SHELX. Acta Crystallogr., Sect. A: Found. Crustallogr. 2008, 64, 112-122.

(31) Sheldrick, G. M. Crystal structure refinement with SHELXL. Acta Crystallogr., Sect. C: Struct. Chem. 2015, 71, 3-8. 